\title{
RPNs Levels are Prognostic and Diagnostic Markers for Hepatocellular Carcinoma
}

\section{Wangyang zheng}

Second Affiliated Hospital of Harbin Medical University https://orcid.org/0000-0003-2936-9509

\section{Yuling Zheng}

Second Affiliated Hospital of Harbin Medical University

\section{Xue Bai}

Shenzhen University

\section{Yongxu Zhou}

Second Affiliated Hospital of Harbin Medical University

\section{Liang Yu}

Second Affiliated Hospital of Harbin Medical University

\section{Daolin Ji}

Harbin Medical University

\section{Kaiming Leng}

Qingdao Municipal Hospital Group

\section{Nanfeng Meng}

Second Affiliated Hospital of Harbin Medical University

\section{Hang Wang}

Second Affiliated Hospital of Harbin Medical University

\section{ZiYue Huang}

Second Affiliated Hospital of Harbin Medical University

\section{Judy Wai Ping Yam}

University of Hong Kong https://orcid.org/0000-0001-7291-3026

\section{Yi Xu ( $\nabla$ xuyihrb@pathology.hku.hk)}

Second Affiliated Hospital of Harbin Medical University https://orcid.org/0000-0003-2720-0005

\section{Yunfu Cui}

Second Affiliated Hospital of Harbin Medical University

\section{Primary research}

Keywords: Hepatocellular carcinoma, RPN, therapeutic target, biomarker

Posted Date: November 23rd, 2021 
DOI: https://doi.org/10.21203/rs.3.rs-1071357/v1

License: (c) (1) This work is licensed under a Creative Commons Attribution 4.0 International License. Read Full License 


\section{Abstract}

Background: Ribophorin family (RPNs) are important regulatory subunits of the proteasome. By influencing Ubiquitin-proteasome system activity, RPNs are responsible for almost all processes of physiology and pathology of mammalian cells. Nevertheless, little is known about the role of RPNs in HCC.

Methods: In this work, using the online databases Oncomine, UCSC, Kaplan-Meier Plotter, UALCAN, cBioPortal, TIMER2, GeneMANIA, and STRING, we first evaluated the expression, diagnostic, prognostic, genetic alteration, immunity, gene network, and functional enrichment of RPNs in HCC. QPCR and western blot were used to detect RPN6 and RPN9 expressions in HCC tissues and cell lines. Then we performed studies to eveulated their functions in HCC cells proliferation, migration, and invasion in vitro.

Results: All RPNs were surprisingly consistently upregulated in HCC tissues. Moreover, RPNs expression pattern is correlated with HCC tumor grade. RPN2, RPN3, RPN6, RPN9, RPN10, RPN11, and RPN12 have robust values in HCC diagnose. Then, survival analysis revealed that high expression of RPN1, RPN2, RPN4, RPN5, RPN6, RPN9, and RPN11 were correlated with unfavorable HCC overall survival. Functional enrichment for RPNs, indicated that RPNs have many potential biosynthesis activities expert for UPS functions. Western blot, and qRT-PCR further verified these results in HCC tissues and cell lines. The silencing of RPN6 and RPN9 significantly influenced HCC cells' proliferation, migration, and invasion in vitro.

Conclusions: RPN families functions as an important oncogene in HCC. RPN6 and RPN9 have the potential to be potential biomarkers and targets for HCC.

\section{Introduction}

Hepatocellular carcinoma (HCC) ranks as the fifth most common cancer and the second cause of cancerrelated death worldwide [1, 2]. In the last 2 decades, the incidence of HCC is increasing globally, while even doubling in the United States [3]. Although surgery has become a standard treatment of HCC, due to its asymptomatic characteristic, most patients have reached late-stage when diagnosed and are not surgical candidates $[4,5]$. The 5 -y survival rate for patients with HCC is only $7 \%$. Therefore, it is an urge to find new biomarkers for detection, diagnosis, prognosis and targets for molecule therapy [6].

The ubiquitin-proteasome system (UPS) is highly conserved in all kinds of eukaryotic cells [7]. Functioning as degrading cellular proteins, UPS is responsible for almost all cellular progress. The incorrect protein degradation may give rise to many diseases including cancers in versatile ways, which have been reported in proliferation, autophagy, and drug resistance $[8,9,10]$. The Ribophorin family have fourteen members: RPN1, RPN2, RPN3/PSMD3, RPN4/PSMD9, RPN5/PSMD12, RPN6/PSMD11, RPN7/PSMD6, RPN8/PSMD7, RPN9/PSMD13, RPN10/PSMD4, RPN11/PSMD14, RPN12/PSMD8, RPN13/ADRM1, and RPN14/ PAAF1. They construct the 19s (regulatory particles) of the 26s proteasome. For some subunits (RPN1, RPN10, and RPN13), their specificity structure and location even determined 
whether proteasome work or not and which protein should be got into degradation [11]. Therefore, many RPNs have been found deregulated and have robust oncogene functions in cancers $[12,13,14,15]$. Moreover, some studies reported that RPNs expression increased after virus infection [16]. As we all know, most HCC patients are initiated by chronic liver hepatitis virus $B$ or $\mathrm{C}$ infections. Therefore, it seems like RPNs may do something special in HCC pathology [17]. Thanks to microarray and RNA-sequencing technology, many cancer targets, and new biomarkers have been identified and verified $[18,19]$. In this study, we extended the knowledge on RPNs and HCC to appraise distinct prognostic values, predict potential functions and putative targets, then evaluate by experiments.

\section{Materials And Methods}

\section{Specimens and cell lines}

Between January 2016 and January 2017, 54 HCC specimens and corresponding non-cancerous tissues were harvested from patients at the Second Affiliated Hospital of Harbin Medical University. These fresh specimens were preserved in liquid nitrogen. None of the patients received radiotherapy, chemotherapy before surgery. This study was authorized by the Ethics Committee of the Second Affiliated Hospital of Harbin Medical University. Hcclm3, Huh7, and Wrl-68 cells were obtained from the Cell Bank of the Chinese Academy of Sciences (Shanghai, China). Hcclm3 and Huh7 were maintained in DMEM (Gibco, Grand Island, NY, USA) containing 10\% fetal bovine serum (Invitrogen Life Technologies, Carlsbad, CA, USA), while Wrl-68 cells in RPMI-1640 (Gibco, Grand Island, NY, USA). They were all cultured in an atmosphere of $37^{\circ} \mathrm{C}$ with $5 \% \mathrm{CO}^{2}$.

\section{Cell transfection and RNA isolation}

Small -hairpin RNA directed against RPN6 and RPN9 were designed and synthesized by (Gene Chem, Shanghai, China). Their sequences are listed in Table S1. An empty Sh-NC vector was used as a control. The procedure of lentiviral infection was conducted by the instructions of the manufacturer. The selection of qualified cells was performed by using puromycin for 3-4 weeks. TRIzol (Sigma, MO, USA) was used for total RNA isolation in HCC tissue specimens and cultured cells. Then we checked the many features such as Nucleic Acid concentration, OD230, OD260, and OD280 of RNAs.

\section{QRT-PCR and Western blotting}

RNAs were applied to synthesize the complementary DNA (cDNA) with a First Strand cDNA Synthesis Kit (Roche, Germany). RT-qPCR was carried out by using the FastStart Universal SYBR Green Master Kit (Roche, Germany). The primer sequences are listed in Table S1. GAPDH was used for the internal control of RNA expression. Sequences of all of the genes primers were listed in Table S1. The mRNA fold change data were normalized and calculated by using equation $2-\triangle \triangle \mathrm{CT}$. Western blot was carried out following standard protocols as previously described [21]

\section{CCK-8 and Wound scratch assay}


CCK-8 (Cell counting kit-8) (Dojindo, Japan) was employed to determine cells viability. A density of $4 \times$ $10^{4}$ cells per well was seeded in 96-well plates. $10 \mu \mathrm{l}$ of reagent was added to each well and maintained for $2 \mathrm{~h}$ at $37^{\circ} \mathrm{C}$. At $0,24,48,72$, and $96 \mathrm{~h}$. Then cells were measured by the reader (Tecan, Switzerland) at a wavelength of $450 \mathrm{~nm}$. Cell motility was measured by Wound scratch experiments. Using a $200 \mu \mathrm{L}$ pipette tube, we created an acellular area. Then, cells were placed in a serum-free DMEM medium. The area was measured at 0,24 , and $36 \mathrm{~h}$.

\section{Migration and invasion assays}

Coated with Matrigel (for invasion) or not (for migration), transwell chambers (Corning, New York, USA) were applied to further access cellular motility. $5 \times 10^{4}$ cells were resuspended in $200 \mu \mathrm{L}$ of FBS-free DMEM in the higher chambers while lower champers were placed with $600 \mu \mathrm{L} 10 \%$ FBS DMEM. After incubating for $48 \mathrm{~h}$ at $37^{\circ} \mathrm{C}$, cells on the upper surface of the chambers were eliminated. Then, cells passed through the membranes were fixed and stained. The numbers of invasive or migrated cells were counted using a microscope.

\section{ONCOMINE analysis}

To analyze the relative expression of RPNs in a variety of tumors, ONCOMINE, a free open-access in-depth bioinformatic database (www.ONCOMINE.org), which was used which includes 715 datasets and 86,733 samples. The mRNA expression profiles of RPNs in HCC were confirmed by this database, using a students' t-test to generate a p-value [20].

\section{UALCAN database}

UALCAN (http://ualcan.path.uab.edu), is an easy-to-use online tool to analyze online microarray data from TCGA databases [21]. Besides, they also provide some clinical features and survival prognosis data based on gene expression differences in 31 cancer types. In our study, we analyzed the expression pattern of RPNs in HCC and the relationships between RPN's mRNA expression pattern and patients' tumor grades. Moreover, we used Bonferroni correction to test $P$-value significance

\section{UCSC Xena}

UCSC Xena, (https://xena.ucsc.edu/) is a free and open-access online tool for getting homogenized data from multiply databases, including TCGA, ICGC, TARGET, GTEx, CCL, etc (22). The database is available to provide information on copy number, methylation, somatic mutation, gene expression, protein expression as well as clinical information.

\section{Kaplan-Meier Plotter database}

The Kaplan-Meier Plotter (http://kmplot.com/analysis/) is an online tool established by TCGA patient survival information, was used to evaluate the prognostic value of RPNs in HCC [23]. The prognostic value was evaluated by four indexes, OS (overall survival), PFS (progression-free survival), RFS (recurrence-free survival), DSS (disease-specific survival).

\section{Cbioportal Analysis}


Cbioportal database (http://www.cbioportal.org/) is an open-access platform that provides interactive exploration of multidimensional Cancer Genomics data [24]. We analyzed the genetic alterations of RPN family genes in HCC based on the 8 studies, which contain 1308 samples. Genomic profiles, mutations, survival data, and mRNA expressions were mentioned for analyzing the fourteen RPN family genes.

\section{GeneMANIA Analysis}

GeneMANIA (www.genemania.org) is an online analytics platform for deriving hypothesis genes interaction networks based on those locations or functions. By querying a list of genes, GeneMANIA can generate multiply genes with similar functions and illustrate the relationship between a queried gene set and the data set by constructing an interactive network (25). In this study, we used GeneMANIA to construct a gene-gene interaction network for RPNs.

\section{Statistical analysis}

We used GraphPad Prism 5.01 software and SPSS 22.0 to analyze the data in this study. The diagnose value of RPNs was measured by ROC curves, which were plotted using the SPSS software. Quantitative data were expressed as mean \pm S.D.

\section{Results}

\section{All RPN's transcriptional levels are extremely high in cancer tissues}

We first analyzed all of the RPN1-RPN14 mRNA expression levels in multiple human cancers using the Oncomine database (Figure 1). The analysis showed that the transcriptional levels of all RPNs were upregulated in human cancers. Some RPNs such as RPN10 and RPN11 were showed up-regulated in HCC patients.

\section{Relationship Between the Transcriptional Levels of RPNs and the Clinicopathological Parameters of HCC Patients}

Then, we compared RPNs' transcriptional levels in HCC with those in normal samples by using UALCAN database (Figure 2). It was found all RPNs were surprisingly consistently upregulated in HCC tissues than normal with a low P-value. After Bonferroni correction, the P-value of all RPNs is still lower than the corrected $(P<0.003571)$. Moreover, we examined our findings in ONCOMINE database (Table 1). In Roessler's dataset, RPN1 was upregulated with a fold change of 1.249 ( $p=1.09 E-14)$, RPN2 with a fold change of $1.713(p=1.54 E-74)$, RPN3 with a fold change of $1.286(p=7.37 E-17)$, RPN4 with a fold change of $1.239(p=7.50 E-11)$, RPN5 with a fold change of $1.692(p=5.83 E-37)$, RPN6 with a fold change of $1.654(p=3.73 E-36)$, RPN7 with a fold change of $1.465(p=1.02 E-23)$, RPN8 with a fold change of $1.162(p=9.26 E-6)$ RPN9 with a fold change of $1.458(p=4.73 E-29)$, RPN10 with a fold change of 2.265( $p=2.10 E-85)$, RPN11 with a fold change of 2.243( $p=4.71 E-74)$, RPN12 with a fold change of 1.543( $p=7.28 E-31)$, RPN13 with a fold change of 1.288( $p=1.40 E-19)$, RPN14 with a fold change of 1.131 
$(p=3.89 \mathrm{E}-5)$, which in sympathy with our finding [27]. Next, using UALCAN database, we analyzed whether the RPNs transcriptional levels were related to clinicopathological characteristics (Figure 3). As shown in figure 3, when tumor grade increases, RPNs expression pattern is also increased. The mRNA levels of all RPNs were positive to tumor differentiation with $p<0.05$. That means the measurement of RPNs level may help to determine the patient's tumor stage. 
Table 1

The significant changes of RPNs expression in the transcriptional level between cancer and normal tissues (Oncomine Database)

\begin{tabular}{|c|c|c|c|c|c|}
\hline $\begin{array}{l}\text { Gene } \\
\text { ID }\end{array}$ & Types of HCC versus normal & $\begin{array}{l}\text { Fold } \\
\text { Change }\end{array}$ & $P$-Value & t-Test & References \\
\hline \multirow[t]{2}{*}{ RPN1 } & $\begin{array}{l}\text { Hepatocellular Carcinoma versus } \\
\text { Normal }\end{array}$ & 1.249 & $1.09 \mathrm{E}^{-14}$ & 7.904 & Roessler [27] \\
\hline & $\begin{array}{l}\text { Hepatocellular Carcinoma versus } \\
\text { Normal }\end{array}$ & 1.019 & 0.024 & 2.009 & TCGA \\
\hline \multirow[t]{6}{*}{ RPN2 } & $\begin{array}{l}\text { Hepatocellular Carcinoma versus } \\
\text { Normal }\end{array}$ & 1.713 & $1.54 \mathrm{E}^{-74}$ & 22.605 & Roessler ${ }^{[27]}$ \\
\hline & $\begin{array}{l}\text { Hepatocellular Carcinoma versus } \\
\text { Normal }\end{array}$ & 1.468 & $3.44 \mathrm{E}^{-7}$ & 5.927 & Roessler [29] \\
\hline & $\begin{array}{l}\text { Hepatocellular Carcinoma versus } \\
\text { Normal }\end{array}$ & 1.022 & $3.27 \mathrm{E}^{-4}$ & 3.790 & $\begin{array}{l}\text { Guichard } \\
\text { [28] }\end{array}$ \\
\hline & $\begin{array}{l}\text { Hepatocellular Carcinoma versus } \\
\text { Normal }\end{array}$ & 1.074 & $1.41 \mathrm{E}^{-8}$ & 6.045 & TCGA \\
\hline & $\begin{array}{l}\text { Hepatocellular Carcinoma versus } \\
\text { Normal }\end{array}$ & 1.033 & $2.13 \mathrm{E}^{-5}$ & 4.248 & $\begin{array}{l}\text { Guichard } \\
\text { [28] }\end{array}$ \\
\hline & $\begin{array}{l}\text { Hepatocellular Carcinoma versus } \\
\text { Normal }\end{array}$ & 1.465 & 0.012 & 2.546 & $\begin{array}{l}\text { Wurmbach } \\
\text { [29] }\end{array}$ \\
\hline \multirow[t]{4}{*}{ RPN3 } & $\begin{array}{l}\text { Hepatocellular Carcinoma versus } \\
\text { Normal }\end{array}$ & 1.231 & 0.001 & 3.074 & Chen ${ }^{[30]}$ \\
\hline & $\begin{array}{l}\text { Hepatocellular Carcinoma versus } \\
\text { Normal }\end{array}$ & 1.286 & $7.37 \mathrm{E}^{-17}$ & 8.617 & Roessler [29] \\
\hline & $\begin{array}{l}\text { Hepatocellular Carcinoma versus } \\
\text { Normal }\end{array}$ & 1.046 & 0.001 & 3.165 & TCGA \\
\hline & $\begin{array}{l}\text { Hepatocellular Carcinoma versus } \\
\text { Normal }\end{array}$ & 1.020 & 0.009 & 2.414 & $\begin{array}{l}\text { Guichard } \\
\text { [28] }\end{array}$ \\
\hline \multirow[t]{3}{*}{ RPN4 } & $\begin{array}{l}\text { Hepatocellular Carcinoma versus } \\
\text { Normal }\end{array}$ & 1.112 & 0.010 & 2.337 & Chen ${ }^{[30]}$ \\
\hline & $\begin{array}{l}\text { Hepatocellular Carcinoma versus } \\
\text { Normal }\end{array}$ & 1.239 & $7.50 \mathrm{E}^{-11}$ & 6.573 & Roessler [27] \\
\hline & $\begin{array}{l}\text { Hepatocellular Carcinoma versus } \\
\text { Normal }\end{array}$ & 1.256 & 0.023 & 2.058 & Roessler [27] \\
\hline \multirow[t]{2}{*}{ RPN5 } & $\begin{array}{l}\text { Hepatocellular Carcinoma versus } \\
\text { Normal }\end{array}$ & 1.692 & $5.83 \mathrm{E}^{-37}$ & 13.892 & Roessler ${ }^{[27]}$ \\
\hline & $\begin{array}{l}\text { Hepatocellular Carcinoma versus } \\
\text { Normal }\end{array}$ & 1.110 & $2.46 \mathrm{E}^{-9}$ & 6.430 & TCGA \\
\hline
\end{tabular}




\begin{tabular}{|c|c|c|c|c|c|}
\hline \multirow[t]{4}{*}{$\begin{array}{l}\text { Gene } \\
\text { ID }\end{array}$} & Types of HCC versus normal & $\begin{array}{l}\text { Fold } \\
\text { Change }\end{array}$ & $P$-Value & $\mathrm{t}$-Test & References \\
\hline & $\begin{array}{l}\text { Hepatocellular Carcinoma versus } \\
\text { Normal }\end{array}$ & 1.042 & $9.93 \mathrm{E}^{-7}$ & 4.986 & $\begin{array}{l}\text { Guichard } \\
{[28]}\end{array}$ \\
\hline & $\begin{array}{l}\text { Hepatocellular Carcinoma versus } \\
\text { Normal }\end{array}$ & 1.034 & 0.005 & 2.778 & $\begin{array}{l}\text { Guichard } \\
\text { [28] }\end{array}$ \\
\hline & $\begin{array}{l}\text { Hepatocellular Carcinoma versus } \\
\text { Normal }\end{array}$ & 1.153 & 0.020 & 2.062 & Chen ${ }^{[30]}$ \\
\hline \multirow[t]{5}{*}{ RPN6 } & $\begin{array}{l}\text { Hepatocellular Carcinoma versus } \\
\text { Normal }\end{array}$ & 1.414 & $1.00 \mathrm{E}^{-8}$ & 5.881 & Chen ${ }^{[30]}$ \\
\hline & $\begin{array}{l}\text { Hepatocellular Carcinoma versus } \\
\text { Normal }\end{array}$ & 1.654 & $3.73 \mathrm{E}^{-36}$ & 13.732 & Roessler ${ }^{[27]}$ \\
\hline & $\begin{array}{l}\text { Hepatocellular Carcinoma versus } \\
\text { Normal }\end{array}$ & 1.407 & 0.011 & 2.571 & $\begin{array}{l}\text { Wurmbach } \\
\text { [29] }\end{array}$ \\
\hline & $\begin{array}{l}\text { Hepatocellular Carcinoma versus } \\
\text { Normal }\end{array}$ & 1.041 & 0.006 & 2.590 & TCGA \\
\hline & $\begin{array}{l}\text { Hepatocellular Carcinoma versus } \\
\text { Normal }\end{array}$ & 1.011 & 0.024 & 1.997 & $\begin{array}{l}\text { Guichard } \\
{[28]}\end{array}$ \\
\hline RPN7 & $\begin{array}{l}\text { Hepatocellular Carcinoma versus } \\
\text { Normal }\end{array}$ & 1.465 & $1.02 \mathrm{E}^{-23}$ & 10.595 & Roessler [27] \\
\hline \multirow[t]{2}{*}{ RPN8 } & $\begin{array}{l}\text { Hepatocellular Carcinoma versus } \\
\text { Normal }\end{array}$ & 1.162 & $9.26 \mathrm{E}^{-6}$ & 4.329 & Roessler [27] \\
\hline & $\begin{array}{l}\text { Hepatocellular Carcinoma versus } \\
\text { Normal }\end{array}$ & 1.373 & 0.014 & 2.375 & $\begin{array}{l}\text { Wurmbach } \\
\text { [29] }\end{array}$ \\
\hline \multirow[t]{2}{*}{ RPN9 } & $\begin{array}{l}\text { Hepatocellular Carcinoma versus } \\
\text { Normal }\end{array}$ & 1.458 & $4.73 \mathrm{E}^{-29}$ & 12.000 & Roessler ${ }^{[27]}$ \\
\hline & $\begin{array}{l}\text { Hepatocellular Carcinoma versus } \\
\text { Normal }\end{array}$ & 1.400 & 0.016 & 2.422 & $\begin{array}{l}\text { Wurmbach } \\
\text { [29] }\end{array}$ \\
\hline \multirow[t]{4}{*}{ RPN10 } & $\begin{array}{l}\text { Hepatocellular Carcinoma versus } \\
\text { Normal }\end{array}$ & 2.265 & $2.10 \mathrm{E}^{-85}$ & 25.343 & Roessler [27] \\
\hline & $\begin{array}{l}\text { Hepatocellular Carcinoma versus } \\
\text { Normal }\end{array}$ & 2.533 & $1.20 \mathrm{E}^{-11}$ & 9.023 & $\begin{array}{l}\text { Wurmbach } \\
\text { [29] }\end{array}$ \\
\hline & $\begin{array}{l}\text { Hepatocellular Carcinoma versus } \\
\text { Normal }\end{array}$ & 2.078 & $1.66 \mathrm{E}^{-11}$ & 9.550 & Roessler [27] \\
\hline & $\begin{array}{l}\text { Hepatocellular Carcinoma versus } \\
\text { Normal }\end{array}$ & 1.097 & $9.63 \mathrm{E}^{-7}$ & 6.126 & $\begin{array}{l}\text { Guichard } \\
{[28]}\end{array}$ \\
\hline
\end{tabular}




\begin{tabular}{|c|c|c|c|c|c|}
\hline \multirow[t]{4}{*}{$\begin{array}{l}\text { Gene } \\
\text { ID }\end{array}$} & Types of HCC versus normal & $\begin{array}{l}\text { Fold } \\
\text { Change }\end{array}$ & $P$-Value & $\mathrm{t}$-Test & References \\
\hline & $\begin{array}{l}\text { Hepatocellular Carcinoma versus } \\
\text { Normal }\end{array}$ & 1.098 & $9.44 \mathrm{E}^{-18}$ & 10.186 & $\begin{array}{l}\text { Guichard } \\
\text { [28] }\end{array}$ \\
\hline & $\begin{array}{l}\text { Hepatocellular Carcinoma versus } \\
\text { Normal }\end{array}$ & 1.318 & $2.06 \mathrm{E}^{-18}$ & 10.720 & TCGA \\
\hline & $\begin{array}{l}\text { Hepatocellular Carcinoma versus } \\
\text { Normal }\end{array}$ & 1.340 & $8.84 \mathrm{E}^{-5}$ & 4.036 & [31] \\
\hline \multirow[t]{4}{*}{ RPN11 } & $\begin{array}{l}\text { Hepatocellular Carcinoma versus } \\
\text { Normal }\end{array}$ & 2.243 & $4.71 \mathrm{E}^{-74}$ & 22.195 & Roessler [27] \\
\hline & $\begin{array}{l}\text { Hepatocellular Carcinoma versus } \\
\text { Normal }\end{array}$ & 2.061 & $3.84 \mathrm{E}^{-7}$ & 5.876 & Roessler [27] \\
\hline & $\begin{array}{l}\text { Hepatocellular Carcinoma versus } \\
\text { Normal }\end{array}$ & 1.266 & $5.88 \mathrm{E}^{-5}$ & 3.941 & Chen ${ }^{[30]}$ \\
\hline & $\begin{array}{l}\text { Hepatocellular Carcinoma versus } \\
\text { Normal }\end{array}$ & 1.723 & 0.008 & 2.864 & $\begin{array}{l}\text { Wurmbach } \\
\text { [29] }\end{array}$ \\
\hline \multirow[t]{5}{*}{ RPN12 } & $\begin{array}{l}\text { Hepatocellular Carcinoma versus } \\
\text { Normal }\end{array}$ & 1.543 & $7.28 \mathrm{E}^{-31}$ & 12.413 & Roessler [27] \\
\hline & $\begin{array}{l}\text { Hepatocellular Carcinoma versus } \\
\text { Normal }\end{array}$ & 1.477 & 0.003 & 2.928 & Roessler [27] \\
\hline & $\begin{array}{l}\text { Hepatocellular Carcinoma versus } \\
\text { Normal }\end{array}$ & 1.148 & 0.007 & 2.507 & Chen ${ }^{[30]}$ \\
\hline & $\begin{array}{l}\text { Hepatocellular Carcinoma versus } \\
\text { Normal }\end{array}$ & 1.031 & 0.002 & 2.981 & TCGA \\
\hline & $\begin{array}{l}\text { Hepatocellular Carcinoma versus } \\
\text { Normal }\end{array}$ & 1.015 & 0.033 & 1.854 & $\begin{array}{l}\text { Guichard } \\
{[28]}\end{array}$ \\
\hline \multirow[t]{6}{*}{ RPN13 } & $\begin{array}{l}\text { Hepatocellular Carcinoma versus } \\
\text { Normal }\end{array}$ & 1.044 & $3.63 \mathrm{E}^{-5}$ & 4.500 & $\begin{array}{l}\text { Guichard } \\
\text { [28] }\end{array}$ \\
\hline & $\begin{array}{l}\text { Hepatocellular Carcinoma versus } \\
\text { Normal }\end{array}$ & 1.091 & $5.17 \mathrm{E}^{-10}$ & 6.763 & TCGA \\
\hline & $\begin{array}{l}\text { Hepatocellular Carcinoma versus } \\
\text { Normal }\end{array}$ & 1.288 & $1.40 \mathrm{E}^{-19}$ & 9.407 & Roessler [27] \\
\hline & $\begin{array}{l}\text { Hepatocellular Carcinoma versus } \\
\text { Normal }\end{array}$ & 1.371 & 0.002 & 3.094 & Roessler [27] \\
\hline & $\begin{array}{l}\text { Hepatocellular Carcinoma versus } \\
\text { Normal }\end{array}$ & 1.174 & 0.007 & 2.487 & Chen ${ }^{[30]}$ \\
\hline & $\begin{array}{l}\text { Hepatocellular Carcinoma versus } \\
\text { Normal }\end{array}$ & 1.030 & 0.001 & 3.126 & $\begin{array}{l}\text { Guichard } \\
\text { [28] }\end{array}$ \\
\hline
\end{tabular}




\begin{tabular}{|llllll|}
\hline $\begin{array}{l}\text { Gene } \\
\text { ID }\end{array}$ & Types of HCC versus normal & $\begin{array}{l}\text { Fold } \\
\text { Change }\end{array}$ & P-Value & t-Test & References \\
\hline RPN144 & $\begin{array}{l}\text { Hepatocellular Carcinoma versus } \\
\text { Normal }\end{array}$ & 1.343 & 0.007 & 2.657 & $\begin{array}{l}\text { Wurmbach } \\
{[29]}\end{array}$ \\
\hline & $\begin{array}{l}\text { Hepatocellular Carcinoma versus } \\
\text { Normal }\end{array}$ & 1.131 & $3.89 \mathrm{E}^{-5}$ & 3.994 & Roessler [27] \\
\hline
\end{tabular}

Table 2

The ROC test results of RPN subunits.

\begin{tabular}{|lllll|}
\hline Gene ID & Area & $P$ Value & \multicolumn{2}{l|}{$95 \%$ Confidence Interval } \\
\cline { 4 - 5 } & & & Lower Bound & Upper Bound \\
\hline RPN1 & 0.494 & 0.898 & 0.421 & 0.568 \\
\hline RPN2 & 0.818 & 0.000 & 0.768 & 0.867 \\
\hline RPN3 & 0.728 & 0.000 & 0.676 & 0.780 \\
\hline RPN4 & 0.593 & 0.032 & 0.527 & 0.660 \\
\hline RPN5 & 0.349 & 0.001 & 0.275 & 0.423 \\
\hline RPN6 & 0.704 & 0.000 & 0.650 & 0.759 \\
\hline RPN7 & 0.438 & 0.151 & 0.372 & 0.503 \\
\hline RPN8 & 0.510 & 0.824 & 0.454 & 0.566 \\
\hline RPN9 & 0.650 & 0.001 & 0.585 & 0.715 \\
\hline RPN10 & 0.880 & 0.000 & 0.841 & 0.918 \\
\hline RPN11 & 0.815 & 0.000 & 0.765 & 0.864 \\
\hline RPN12 & 0.620 & 0.006 & 0.556 & 0.683 \\
\hline RPN13 & 0.593 & 0.032 & 0.521 & 0.665 \\
\hline RPN14 & 0.553 & 0.226 & 0.480 & 0.625 \\
\hline
\end{tabular}

\section{Diagnosis and Prognostic significance of the RPNs in HCC}

To evaluate the value of RPNs in the diagnosis of HCC, computing receiver operating characteristic (ROC) analysis was used. By using the data obtained from the HCC platform from the UCSC website, we draw the ROC curves to analyze the RPNs' diagnostic significance. As the figure showed (Figure 4), 
RPN2(Area $=0.818$ and $P<0.0001), R P N 3(A r e a=0.728$ and $P<0.0001), R P N 6(A r e a=0.704$ and $P<0.0001$ ), RPN9(Area $=0.650$ and $P<0.0001$ ), RPN10(Area $=0.880$ and $P<0.0001$ ) and RPN11(Area $=0.815$ and $\mathrm{P}<0.0001$ ) were all helpful for HCC diagnosis. Our finding suggested that RPN2, RPN3, RPN6, RPN9, RPN10, RPN11and RPN12 have the potential to be useful as biomarkers for HCC.

Then we evaluated the prognostic role of RPNs in HCC using Kaplan-Meier Plotter databases (Figure 5). In the OS (overall survival) group, lower RPN1, RPN2, RPN5, RPN6, RPN9, and RPN11 expression indicated better survival. In the PFS (progression-free survival) group, reduced RPN4, RPN5, and RPN11 were correlated with better survival. In the RPS (recurrence-free survival) group, RPN4, RPN5, RPN9, RPN10, and RPN11 downregulating were connected with better survival. In the DSS (disease-specific survival) group, the down-regulation of RPN2, RPN5, RPN9, and RPN11 may indicate better survival. These findings were consistent with the UALCAN analysis and suggested that some RPNs such as RPN5, RPN9, and RPN11 have great prognostic value for HCC.

\section{Genetic Alteration and immune infiltration Analyses of RPNs in HCC Patients}

We used the cBioPortal online tool to analyze genetic changes of RPNs in HCC. According to the TCGA data set, the highest genetic variation rate in RPNs is RPN10 (5\%), the lowest mutation rate is RPN4 $(0.1 \%)$, and the others are RPN8 (0.2\%), RPN14 (0.3\%), RPN1 (0.3\%), RPN3 $(0.3 \%)$ and RPN7 $(0.3 \%)$ (Figure 6A). Although changes are little in RPNS, those changes were correlated with patient overall survival (Figure 6B).

TIMER database is used to evaluate the relationship between the transcription level of RPNs and the level of immune infiltration in HCC. It was found that RPNs are involved in an inflammatory response and immune cell infiltration, which may affect the clinical outcome of HCC patients. The analysis results are shown in Figure 7. RPN2 expression was positively correlated with infiltration of B cells, macrophage, and dendritic cells. RPN4 was negatively correlated with the infiltration of CD4+ T cells. RPN5 was negatively correlated with infiltration of CD4+ T cells, while positively correlated with neutrophil infiltration. E2F6 expressions were positively correlated with the infiltration of macrophages and neutrophils. RPN7 was negatively correlated with infiltration of $C D 8+T$ cells, CD4+ T cells, macrophage, neutrophil, and dendritic. RPN8 was negatively correlated with infiltration of Purity and CD4+ T cells. RPN9 was negatively correlated with the infiltration of CD4+ T cells and neutrophils. RPN10 was positively correlated with the infiltration of purity cells, while negatively correlated CD8+ T cells, CD4+ T cells, macrophage, neutrophil, and dendritic cells. RPN11 was positively correlated with the infiltration of neutrophils, while negatively correlated with purity. RPN12 was positively correlated with the infiltration of CD4+ T cells. RPN13 was negatively correlated with B cells, CD8+ T cells, CD4+ T cells, macrophage, neutrophil, and dendritic cells. RPN14 was positively correlated with the infiltration of purity cells, while negatively with B cells, CD8+ T cells, CD4+ T cells, macrophage, neutrophil, and dendritic cells. These results indicated that the level of RPNs expression is associated with the level of immune infiltration in HCC

\section{The GGI and Functional enrichment of RPNs}


Identifying more details about RPNs could give a boost to an understanding of their potential functions in HCC. Therefore, we constructed GGI by using the GeneMANIA database. In figure 8 , The fourteen central nodes of RPNs are surrounded by 20 genes that are strongly associated with RPNs in physical interactions, co-localization, co-expression, prediction, genetic interactions, and pathways. The top five genes most associated are PSMC1 (proteasome 26S subunit, ATPase 1), PSMC6 (proteasome 26S subunit, ATPase 6), PSMD10 (proteasome 26S subunit, non-ATPase 10), PSMC4 (proteasome 26S subunit, ATPase 4), and PSMC3 (proteasome 26S subunit, ATPase 3). They all have genetic interactions and correlate with functions such as proteasome accessory complex, proteasome complex, regulation of the cellular amino acid metabolic process.

As shown in figure 9, besides protein binding, RNA binding, or ubiquitin-protein ligase activity these UPS functions, RPNs still play important role in biosynthesis: transcription coactivator activity (G0:0003713), translation initiation factor activity (G0:0003743), protein processing in the endoplasmic reticulum (hsa04141) and glycan biosynthesis (hsa00510).

\section{The transcription of RPN6 and RPN9 is specifically up- regulated in HCC}

To confirm our conclusions, we first conducted (RT-qPCR) to investigate mRNA levels of RPN6 and RPN9 in 54 paired human HCC tissue specimens and their corresponding nontumorous tissue samples. The results showed that RPN6 and RPN9 mRNA expression was markedly elevated in HCC tissues relative to normal (Fig. 10a, b). An upregulated protein expression levels of RPN6 and RPN9 were further confirmed in 4 paired specimens by immunoblotting assays (Fig. 10c, d). To further investigate the function of RPN6 and RPN9 in CCA, a panel of human HCC cell lines was evaluated by RT-qPCR. As shown in Fig. 10e, f, RPN6, and RPN9 were present at higher levels in HCC cells (Hcclm3 and Huh7) compared with Wrl68.

\section{Knockdown of RPN6 and RPN9 inhibits cell proliferation, migration, and invasion in vitro}

As RPN6 and RPN9 are upregulated in HCC tissues and cell lines, it is necessary to determine whether their suppression could affect biologic activity in HCC cells. We stably downregulated RPN6 and RPN9 in HCC cell lines Hcclm3 and Huh7 cells using shRNA. As shown in figure 11a, RT-qPCR data indicated that a significant loss of mRNA expression in those two HCC cell lines. The CCK-8 proliferation curves demonstrated that cell growth was remarkedly attenuated by RPN6 and RPN9 knockdown in Hcclm3 and Huh7 cells (figure 11b). We further explored the potential impact of RPN6 and RPN9 knockdown on metastatic properties in HCC cells by using wound scratch and transwell assays. As shown in figure 11c, the results showed that the loss function of RPN6 and RPN9 significantly suppressed the wound closure potential in Hcclm3 and Huh7 cells. In the transwell assay, attenuated RPN6 and RPN9 expression remarkably decreased the capabilities of migration and invasion in Hcclm3 and Huh7 cells. So, our results show that RPN6 and RPN9 expressions are essential for HCC cells proliferation, migration, and invasion. 


\section{Discussion}

Hepatocellular carcinoma, featured by high morbidity and mortality, remains one of the most health threats to people worldwide [2]. Although surgical procedures become the standard of treatment, due to disappointing diagnoses, most patients are not surgical candidates [32]. Therefore, to conquer HCC, screaming potential molecular biomarkers is the top priority.

By charging $80-90 \%$ of proteins degradation, UPS is a sophisticated controlled system and responsible for many kinds of cellular procedures as well as oncogenesis [33,34]. Ribophorin family are important regulatory subunits of $26 \mathrm{~s}$ proteasome. Some studies have reported RPNs deregulation to have robust oncogene functions in multiply cancers $[12,13,14,15]$. Although some RPNs' oncogenic role in HCC has been proved [35, 36, 37], distinct roles of RPNs family in HCC remained ambiguous. Therefore, we performed a comprehensive bioinformatics analysis of RPNs in this study.

Rpn1 is the largest subunit of the proteasome subunit and functioned as the recognition part of ubiquitinproteasome system proteins by the proteasome [38]. RPN1 was possessed by two adjacent regions designated as $\mathrm{T} 1$ and $\mathrm{T} 2$. T1 is the receptor site for certain UBL domain proteins, while T2 binding to USP14, a proteasome-associated deubiquitinating enzyme [39, 40]. As a crucial part of the UPS system, RPN1 was found to be up-regulated in lung and kidney cancer [41]. Abnormal RPN1/EVI1 fusion was also popular in myelodysplasia and acute myeloid leukemia [42]. And could be one of the relevant genes to predict breast cancer prognostic significance [43]. In our study, data from the online datasets showed RPN1 was highly expressed in human HCC tissues compared to normal tissues. And, RPN1 expression is related to tumor grade. Further, highly expressed RPN1 RNA was associated with a worse OS, which is not studied in the previous report.

Located 20ql2-13.1, RPN2 is paralogous Rpn1 and a highly conserved protein in the rough endoplasmic reticulum. In 2008, Takahashi et al reported overexpressed RPN2 is associated with docetaxel resistance by degenerating GSK3b in breast cancer [12]. Tominaga et al found the other drug resistance function of RPN2 in breast cancer with a different target of CD63 [44]. Next, RPN2's oncogene role has been found in esophageal squamous cell carcinoma [13], Osteosarcoma [14], gastric cancer [15], and HCC [36]. The Zhang et al study showed that RPN2 may sever as biomarkers for colorectal cancer, which was accord to our study. Recently, Huang et al identified that RPN2 was upregulated in HCC cell lines and HCC tissues. Overexpressed RPN2 expression increased cell proliferation, metastasis, invasion, and epithelialmesenchymal transition [45]. RPN2 may precisely interact with STAT3 and NF-KB pathways.

Circ_0046599 was also found to promote HCC development by influencing RPN2 [46]. Moreover, as liquid biopsy is a research hotspot, RPN2 can be detected in both in blood exosomes [47] and urinary exosomes [48], which may expand its application in diagnosing.

RPN6 is another important subunit in the UPS system. Studies have proven that its high expression or phosphorylation may promote proteasome activity $[49,50]$. And RPN6 could protect pancreatic cancer cells from acute apoptosis [51]. In our work, we indicted that RPN6 was up-regulated in HCC. And its expression level is correlated with the patient's tumor grade and OS. Moreover, RPN6 is a sensitivity 
biomarker for HCC diagnoses. Previous studies thought RPN9 is an aging-related gene [52, 53]. Our study first revealed the oncogene role of RPN9 in cancers. Further work should be done to confirm our results.

Besides important subunits of proteasome, RPN11 is also a robust proteasome deubiquitinase. Luo et al reported RPN11 plays an important role in breast cancer progression [54]. Zhu et al showed silencing RPN11 reduced metastasis of esophageal squamous cell carcinoma [55]. Wang et al indicated that RPN11 dysregulation may correlate with many cancers besides HCC [56]. On the expression level, the RPN11 we uncovered here might serve as an effective diagnostic and prognosis biomarker for HCC. In our study, we showed that all members of RPNs were significantly overexpressed in HCC and their expression patterns were connected with the patient's tumor grade. The ROC curve suggested that RPN2, RPN3, RPN6, RPN9, RPN10, RPN11, and RPN12 have both sensitivity and specificity in HCC diagnosis. Moreover, RPN1, RPN2, RPN5, RPN6, RPN9, and RPN11 expression was negatively correlated with patients' OS. Moreover, the level of RPNs expression is associated with the level of immune infiltration in HCC. The GGI, and functional enrichment of RPNs analyzed for predicting their molecular functions and potential targets. Moreover, we performed western blot and qRT-PCR of RPN6 and RPN9 to verify these results. The silencing of RPN6 and RPN9 significantly influenced HCC cells' proliferation, migration, and invasion. Our findings showed that the RPN family has the potential to be new prognostic and diagnostic markers and also drug targets for HCC. There are still some limitations in our study. Our findings required a multicenter, randomized, large clinical controlled trial. And the molecule processes behind RPNs should be addressed either. Moreover, as RPNs can be detected in blood and urinary, the effect of liquid biopsy may be valued in the further. Despite the limitations above, our study first investigated the diagnostic and prognostic value of RPNs in HCC. Their results highlighted many RPNs have the potential to be new biomarkers and underlying targets for HCC

\section{Conclusion}

Our study first investigated the expression, diagnostic, prognostic, genetic alteration, immunity, gene network, and functional enrichment of RPNs in HCC. And we verificated these reults by experiments method. Their results highlighted many RPNs have the potential to be new biomarkers and underlying targets for HCC

\section{Abbreviations}

RPNs: Ribophorin family; HCC: Hepatocellular carcinoma; UPS: Ubiquitin-proteasome system; CCK-8:Cell counting kit-8; ROC: Computing receiver operating characteristic; OS: overall survival; PFS: progressionfree survival; RPS: recurrence-free survival; DSS: disease-specific survival; PSMC1: proteasome 26S subunit, ATPase 1; PSMC6: proteasome $26 S$ subunit, ATPase 6; PSMD10: proteasome 26S subunit, nonATPase 10; PSMC4: proteasome 26S subunit, ATPase 4; PSMC3: proteasome 26S subunit, ATPase 3; TCGA: The Cancer Genome Atlas; GO: Gene Ontology; BP: Biological process; CC: Cellular component; MF: Molecular function; KEGG: Kyoto Encyclopedia of Genes and Genomes 


\section{Declarations}

\section{Ethics approval and consent to participate}

This study was authorized by the Ethics Committee of the Second Affiliated Hospital of Harbin Medical University.

\section{Consent for publication}

Not applicable

\section{Data available statement}

The transcription levels of RPNs and the changes of RPNs expression between cancer and normal" data was downloaded from the Oncomine database (http://www.oncomine.org) under the accession number(s): n8630, n8887, n8302, n4313, n8472 and n9158.

The transcription levels of ITPRs between cancer and normal was downloaded from the UALCAN database (http://ualcan.path.uab.edu)

Cancer patients' survival analysis data was downloaded from the Kaplan-Meier Plotter database (http:IIgepia.cancer-pku.cn).

The RPNs gene expression data and clinic information were downloaded from the UCSC Xena database (https://xena.ucsc.edu/).

The immune infiltrations data was downloaded from the Timer database (https://cistrome.shinyapps.io/timer/)

The RPNs gene alteration data and clinic information were downloaded from the CbioPortal database (http://www.cbioportal.org).

The gene relationships network data was downloaded from the GeneMANIA database (www.genemania.org).

The GO and KEGG enrichment data were downloaded from the STRING database (https://string-db.org/).

The datasets used and/or analysed during the current study are available from the corresponding author upon reasonable request

\section{Competing interests}


The authors have declared that no competing interest exists

\section{Fundings}

This study was funded by National Natural Science Foundation of China (Grant No. 81902431) Special Project of China Postdoctoral Science Foundation (Grant No. 2019T120279); China Postdoctoral Science Foundation (Grant No. 2018M641849 and 2018M640311); Heilongjiang Postdoctoral Science Foundation (Grant No. LBH-Z18107 and LBH-Z18112); Natural Science Foundation of Heilongjiang Province (Grant No. YQ2019H007);Postgraduate Innovative Research Project of Harbin Medical University (Grant No. YJSCX2016-21HYD); Foundation of Key Laboratory of Myocardial Ischemia, Ministry of Education (Grant No. KF201810); Chen Xiaoping Foundation for the Development of Science and Technology of Hubei Province (Grant No. CXPJJH11800004-001 and CXPJJH11800004-003); The Fundamental Research Funds for the Heilongjiang Provincial Universities (Grant No. 2018-KYYWF-0511 and 2018-KYYWF-0498); Hong Kong Scholars Program (Grant No. XJ2020012).

\section{Authors' contributions}

$\mathrm{NM}, \mathrm{HW}, \mathrm{ZY}$, and ML acquired the data from HCC patients and the databases. Wz, XB,and Yz analysed and interpreted the data acquired from the databases, performed the laboratory experiments and were the major contributors in writing the manuscript. YX, JY and YC designed the work.YZ, LY, and DJ supervised the study. All authors read and approved the fnal manuscript.

\section{Acknowledgments}

Not applicable.

\section{References}

1. El-Serag HB. Hepatocellular carcinoma. N Engl J Med. 2011; 365:1118-27.

2. Torre LA, Bray F, Siegel RL, Ferlay J, Lortet-Tieulent J, Jemal A. Global cancer statistics, 2012. CA Cancer J Clin.2015; 65:87-108.

3. Forner A, Reig M, Bruix J. Hepatocellular carcinoma. Lancet. 2018; 391:1301-14.

4. Truty MJ, Vauthey JN. Surgical resection of high-risk hepatocellular carcinoma: patient selection, preoperative considerations, and operative technique. Ann Surg Oncol. 2010; 17:1219-25.

5. Poon RT, Fan ST, Lo CM, Liu CL, Wong J. Long-term survival and pattern of recurrence after resection of small hepatocellular carcinoma in patients with preserved liver function: implications for a strategy of salvage transplantation. Ann Surg. 2002; 235(3):373-82. 
6. Wong CM, Wei L, Law CT, Ho DW, Tsang FH, Au SL, et al. Up-regulation of histone methyltransferase SETDB1 by multiple mechanisms in hepatocellular carcinoma promotes cancer metastasis. Hepatology. 2016; 63:474-87.

7. Weissman AM. Themes and variations on ubiquitylation. Nat Rev Mol Cell Biol. 2001; 2:169-78.

8. Devoy A, Soane T, Welchman R, Mayer RJ. The ubiquitin-proteasome system and cancer. Essays Biochem. 2005; 41:187-203.

9. Wang $X$, Yin L, Yang L, Zheng Y, Liu S, Yang J et al. Silencing ubiquitin-conjugating enzyme 2C inhibits proliferation and epithelial-mesenchymal transition in pancreatic ductal adenocarcinoma. FEBS J. 2019; 286:4889-909.

10. Cloos J, Roeten MS, Franke NE, van Meerloo J, Zweegman S, Kaspers GJ, et al. (Immuno)proteasomes as therapeutic target in acute leukemia. Cancer Metastasis Rev. 2017; 36:599-615.

11. Jiang TX, Zhao M, Qiu XB. Substrate receptors of proteasomes. Biol Rev Camb Philos Soc.2018; 93:1765-1777.

12. Honma K, Iwao-Koizumi K, Takeshita F, Yamamoto Y, Yoshida T, Nishio K, et al. RPN2 gene confers docetaxel resistance in breast cancer. Nat Med. 2008; 14:939-48.

13. Kurashige J, Watanabe M, Iwatsuki M, Kinoshita K, Saito S, Nagai Y, et al. RPN2 expression predicts response to docetaxel in oesophageal squamous cell carcinoma. $\mathrm{Br} J$ Cancer. 2012; 107:1233-8.

14. Fujiwara T, Takahashi RU, Kosaka N, Nezu Y, Kawai A, Ozaki T, et al. RPN2 Gene Confers Osteosarcoma Cell Malignant Phenotypes and Determines Clinical Prognosis. Mol Ther Nucleic Acids. 2014; 3: e189.

15. Yuan TM, Liang RY, Chueh PJ, Chuang SM. Role of ribophorin II in the response to anticancer drugs in gastric cancer cell lines. Oncol Lett. 2015; 9:1861-8.

16. Marceau CD, Puschnik AS, Majzoub K, Ooi YS, Brewer SM, Fuchs G, et al. Genetic dissection of Flaviviridae host factors through genome-scale CRISPR screens. Nature. 2016; 535:159-63.

17. El-Serag HB. Epidemiology of viral hepatitis and hepatocellular carcinoma. Gastroenterology. 2012; 142:1264-73. e1.

18. Peng D, Wei C, Zhang X, Li S, Liang H, Zheng X, et al. Pan-cancer analysis combined with experiments predicts CTHRC1 as a therapeutic target for human cancers. Cancer Cell Int. 2021;21(1):566.

19. Ye Y, Wang J, Liang F, Song P, Yan X, Wu S, Huang X, Han P. Identification of key genes for HNSCC from public databases using bioinformatics analysis. Cancer Cell Int. 2021; 21(1):549.

20. Xu Y, Yao Y, Leng K, Li Z, Qin W, Zhong X, et al. Long non-coding RNA UCA1 indicates an unfavorable prognosis and promotes tumorigenesis via regulating AKT/GSK-3 $\beta$ signaling pathway in cholangiocarcinoma. Oncotarget.2017; 8, 96203-96214.

21. Rhodes DR, Yu J, Shanker K, Deshpande N, Varambally R, Ghosh D, et al. ONCOMINE: a cancer microarray database and integrated data-mining platform. Neoplasia. 2004; 6:1-6. 
22. Chandrashekar DS, Bashel B, Balasubramanya SAH, Creighton CJ, Ponce-Rodriguez I, Chakravarthi BVSK, et al. UALCAN: A Portal for Facilitating Tumor Subgroup Gene Expression and Survival Analyses. Neoplasia. 2017; 19:649-58.

23. Goldman MJ, Craft B, Hastie M, Repečka K, McDade F, Kamath A, et al. Visualizing and interpreting cancer genomics data via the Xena platform. Nat Biotechnol. 2020; 38:675-8.

24. Nagy Á, Lánczky A, Menyhárt O, Győrffy B. Validation of miRNA prognostic power in hepatocellular carcinoma using expression data of independent datasets. Sci Rep. 2018; 8:9227.

25. Cerami E, Gao J, Dogrusoz U, Gross BE, Sumer SO, Aksoy BA, et al. The cBio cancer genomics portal: an open platform for exploring multidimensional cancer genomics data. Cancer Discov. 2012; 2:401-4.

26. Warde-Farley D, Donaldson SL, Comes O, Zuberi K, Badrawi R, Chao P, et al. The GeneMANIA prediction server: biological network integration for gene prioritization and predicting gene function. Nucleic Acids Res. 2010; 38: W214-20.

27. Roessler S, Jia HL, Budhu A, Forgues M, Ye QH, Lee JS, et al. A unique metastasis gene signature enables prediction of tumor relapse in early-stage hepatocellular carcinoma patients. Cancer Res. 2010; 7:10202-12.

28. Guichard C, Amaddeo G, Imbeaud S, Ladeiro Y, Pelletier L, Maad IB, et al. Integrated analysis of somatic mutations and focal copy-number changes identifies key genes and pathways in hepatocellular carcinoma. Nat Genet. 2012; 44:694-8.

29. Wurmbach E, Chen YB, Khitrov G, Zhang W, Roayaie S, Schwartz M, et al. Genome-wide molecular profiles of HCV-induced dysplasia and hepatocellular carcinoma. Hepatology. 2007; 45:938-47.

30. Chen X, Cheung ST, So S, Fan ST, Barry C, Higgins J, et al. Gene expression patterns in human liver cancers. Mol Biol Cell. 2002; 13:1929-39.

31. Mas VR, Maluf DG, Archer KJ, Yanek K, Kong X, Kulik L, et al. Genes involved in viral carcinogenesis and tumor initiation in hepatitis C virus-induced hepatocellular carcinoma. Mol Med. 2009; 15:85-94.

32. Truty MJ, Vauthey JN. Surgical resection of high-risk hepatocellular carcinoma: patient selection, preoperative considerations, and operative technique. Ann Surg Oncol. 2010; 17:1219-25.

33. Shen M, Schmitt S, Buac D, Dou QP. Targeting the ubiquitin-proteasome system for cancer therapy. Expert Opin Ther Targets. 2013; 17:1091-108.

34. Chen YJ, Wu H, Shen XZ. The ubiquitin-proteasome system and its potential application in hepatocellular carcinoma therapy. Cancer Lett. 2016; 379:245-52.

35. Jiang Z, Zhou Q, Ge C, Yang J, Li H, Chen T, et al. Rpn10 promotes tumor progression by regulating hypoxia-inducible factor 1 alpha through the PTEN/Akt signaling pathway in hepatocellular carcinoma. Cancer Lett. 2019; 447:1-11.

36. Huang L, Jian Z, Gao Y, Zhou P, Zhang G, Jiang B, et al. RPN2 promotes metastasis of hepatocellular carcinoma cell and inhibits autophagy via STAT3 and NF-KB pathways. Aging (Albany NY).2019; 11:6674-90. 
37. Kido T, Ou JH, Lau YF. The X-linked tumor suppressor TSPX interacts and promotes degradation of the hepatitis B viral protein HBx via the proteasome pathway. PLoS One. 2011; 6: e22979.

38. Rosenzweig R, Bronner V, Zhang D, Fushman D, Glickman MH. Rpn1 and Rpn2 coordinate ubiquitin processing factors at proteasome. J Biol Chem. 2012; 287:14659-71.

39. Shi Y, Chen X, Elsasser S, Stocks BB, Tian G, Lee BH, et al. Rpn1 provides adjacent receptor sites for substrate binding and deubiquitination by the proteasome. Science.

2016;351(6275):10.1126/science.aad9421 aad9421. doi:10.1126/science.aad9421

40. Brukhin V, Gheyselinck J, Gagliardini V, Genschik P, Grossniklaus U. The RPN1 subunit of the 26S proteasome in Arabidopsis is essential for embryogenesis. Plant Cell. 2005. 17:2723-37.

41. Krasnov GS, Oparina Nlu, Dmitriev AA, Kudriavtsev AV, Anedchenko EA, Kondrat'eva TT, et al. Mol Biol. 2011; 45(2):238-48.

42. Shearer BM, Sukov WR, Flynn HC, Knudson RA, Ketterling RP. Development of a dual-color, double fusion FISH assay to detect RPN1/EVI1 gene fusion associated with inv $(3), t(3 ; 3)$, and ins $(3 ; 3)$ in patients with myelodysplasia and acute myeloid leukemia. Am J Hematol. 2010; 85:569-74.

43. Milde-Langosch K, Karn T, Schmidt M, zu Eulenburg C, Oliveira-Ferrer L, Wirtz RM, et al. Prognostic relevance of glycosylation-associated genes in breast cancer. Breast Cancer Res Treat. 2014; 145:295-305.

44. Tominaga N, Hagiwara K, Kosaka N, Honma K, Nakagama H, Ochiya T. RPN2-mediated glycosylation of tetraspanin CD63 regulates breast cancer cell malignancy. Mol Cancer. 2014; 13:134.

45. Huang L, Jian Z, Gao Y, Zhou P, Zhang G, Jiang B, et al. RPN2 promotes metastasis of hepatocellular carcinoma cell and inhibits autophagy via STAT3 and NF-KB pathways. Aging (Albany NY). 2019;11(17):6674-6690.

46. Fang Q, Liu H, Zhou A, Zhou H, Zhang Z. Circ_0046599 Promotes the Development of Hepatocellular Carcinoma by Regulating the miR-1258/RPN2 Network. Cancer Manag Res. 2020; 12:6849-60.

47. Tauro BJ, Greening DW, Mathias RA, Mathivanan S, Ji H, Simpson RJ. Two distinct populations of exosomes are released from LIM1863 colon carcinoma cell-derived organoids. Mol Cell Proteomics. 2013; 12:587-98.

48. Moon PG, Lee JE, You S, Kim TK, Cho JH, Kim IS et al. Proteomic analysis of urinary exosomes from patients of early IgA nephropathy and thin basement membrane nephropathy. Proteomics. 2011; 11:2459-75.

49. Vilchez D, Boyer L, Morantte I, Lutz M, Merkwirth C, Joyce D, et al. Increased proteasome activity in human embryonic stem cells is regulated by PSMD11. Nature. 2012; 489:304-8.

50. Lokireddy S, Kukushkin NV, Goldberg AL. CAMP-induced phosphorylation of 26S proteasomes on Rpn6/PSMD11 enhances their activity and the degradation of misfolded proteins. Proc Natl Acad Sci U S A. 2015; 112: E7176-85.

51. Qi T, Zhang W, Luan Y, Kong F, Xu D, Cheng G, et al. Proteomic profiling identified multiple short-lived members of the central proteome as the direct targets of the addicted oncogenes in cancer cells. Mol Cell Proteomics. 2014; 13:49-62. 
52. Mancini A, Vitucci D, Randers MB, Schmidt JF, Hagman M, Andersen TR, et al. Lifelong Football Training: Effects on Autophagy and Healthy Longevity Promotion. Front Physiol. 2019; 10:132.

53. Bellizzi D, Dato S, Cavalcante P, Covello G, Di Cianni F, et al. Characterization of a bidirectional promoter shared between two human genes related to aging: SIRT3 and PSMD13. Genomics. 2007; 89:143-50.

54. Luo G, Hu N, Xia X, Zhou J, Ye C. RPN11 deubiquitinase promotes proliferation and migration of breast cancer cells. Mol Med Rep. 2017; 16:331-8.

55. Zhu R, Liu Y, Zhou H, Li L, Li Y, Ding F, et al. Deubiquitinating enzyme PSMD14 promotes tumor metastasis through stabilizing SNAIL in human esophageal squamous cell carcinoma. Cancer Lett. 2018; 418:125-34.

56. Wang CH, Lu SX, Liu LL, Li Y, Yang X, He YF, et al. POH1 Knockdown Induces Cancer Cell Apoptosis via p53 and Bim. Neoplasia. 2018; 20:411-24.

\section{Figures}

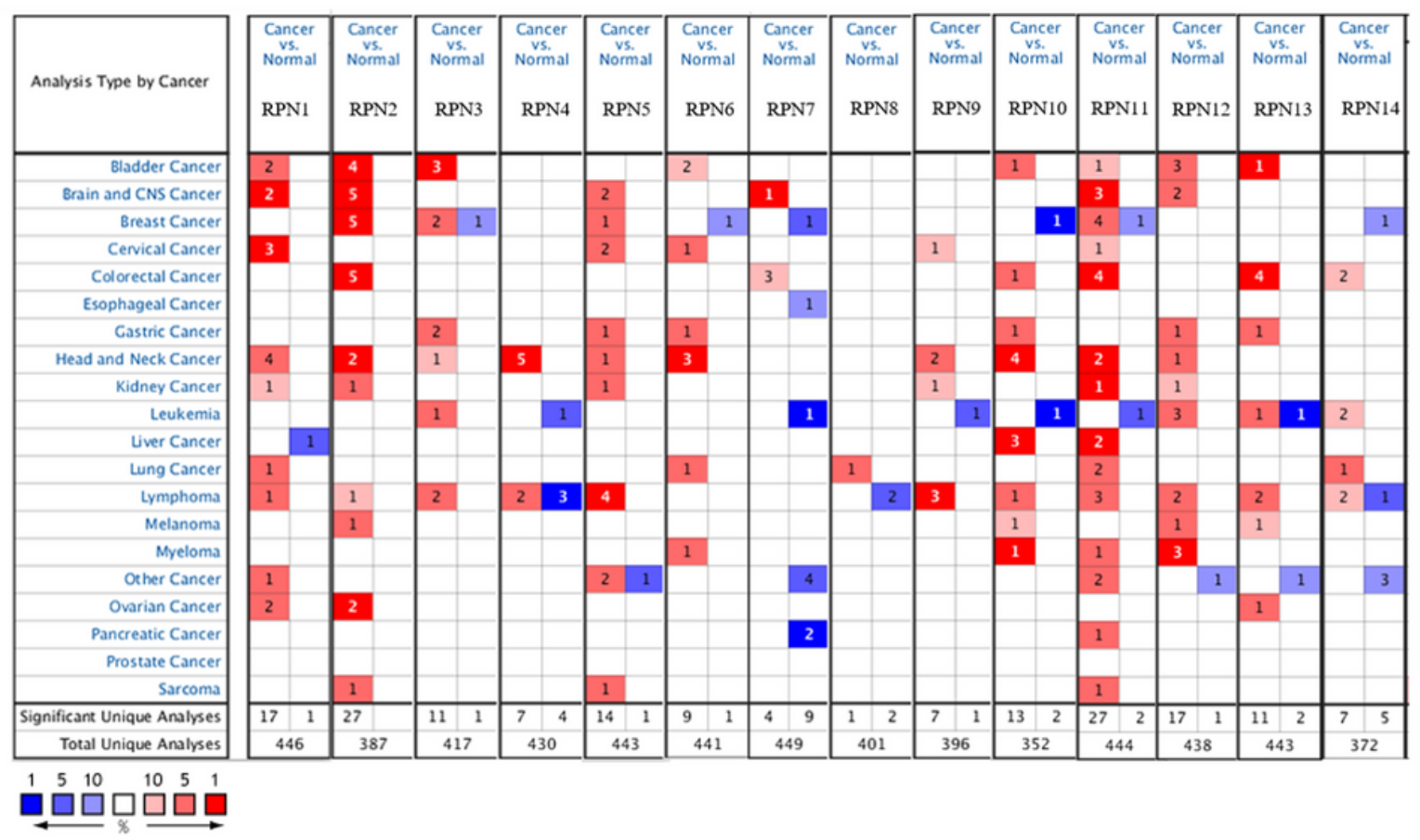

\section{Figure 1}

The transcription levels of RPNs in different types of cancers (ONCOMINE). 


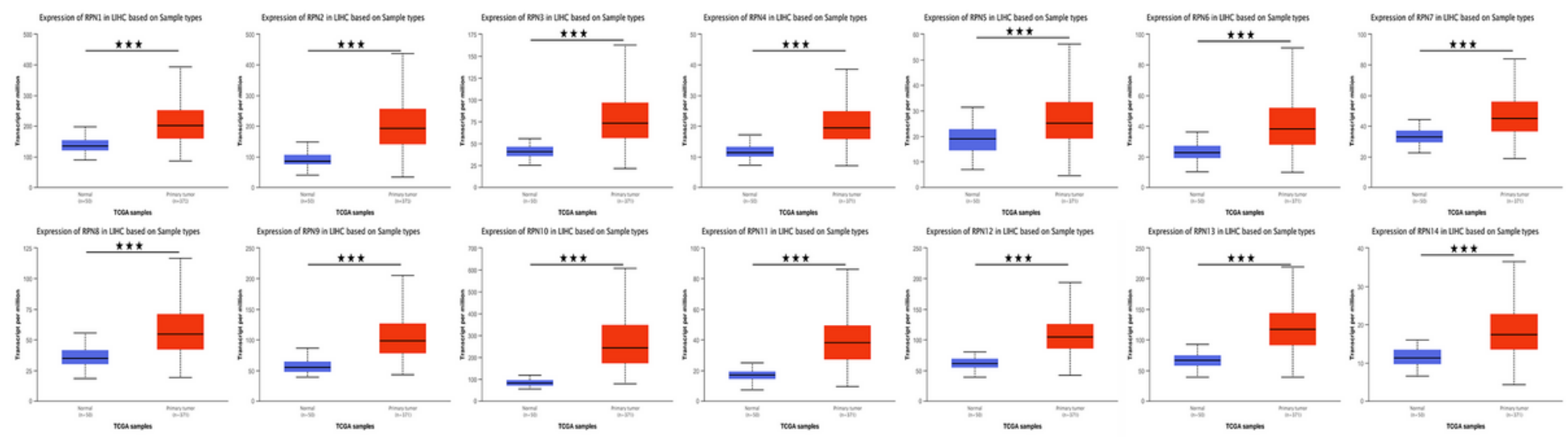

Figure 2

The expression of RPN family members in HCC patients (UALCAN)
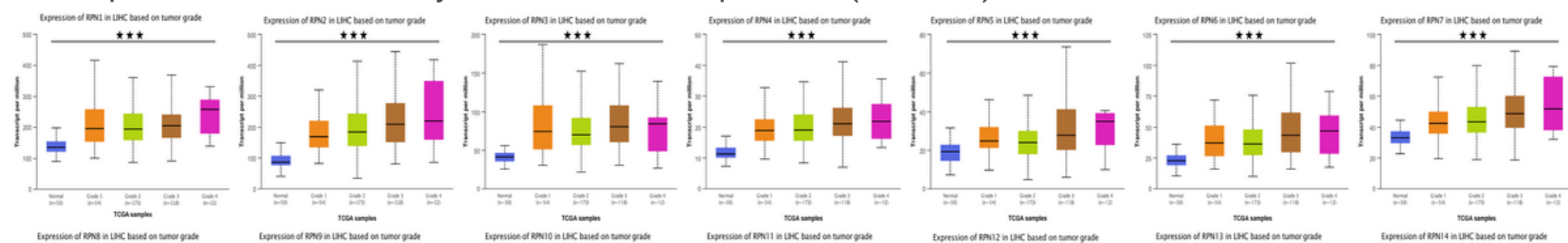

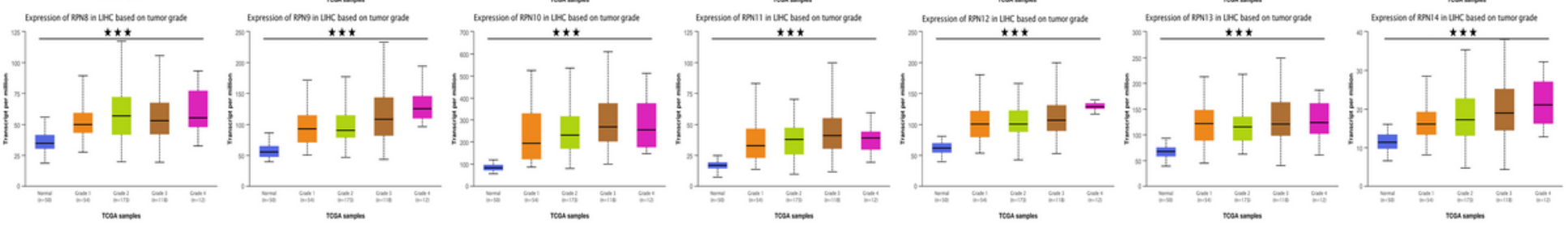

Figure 3

Correlation between levels of RPNs and HCC patient tumor grade. (UALCAN) 


\section{ROC Curve}

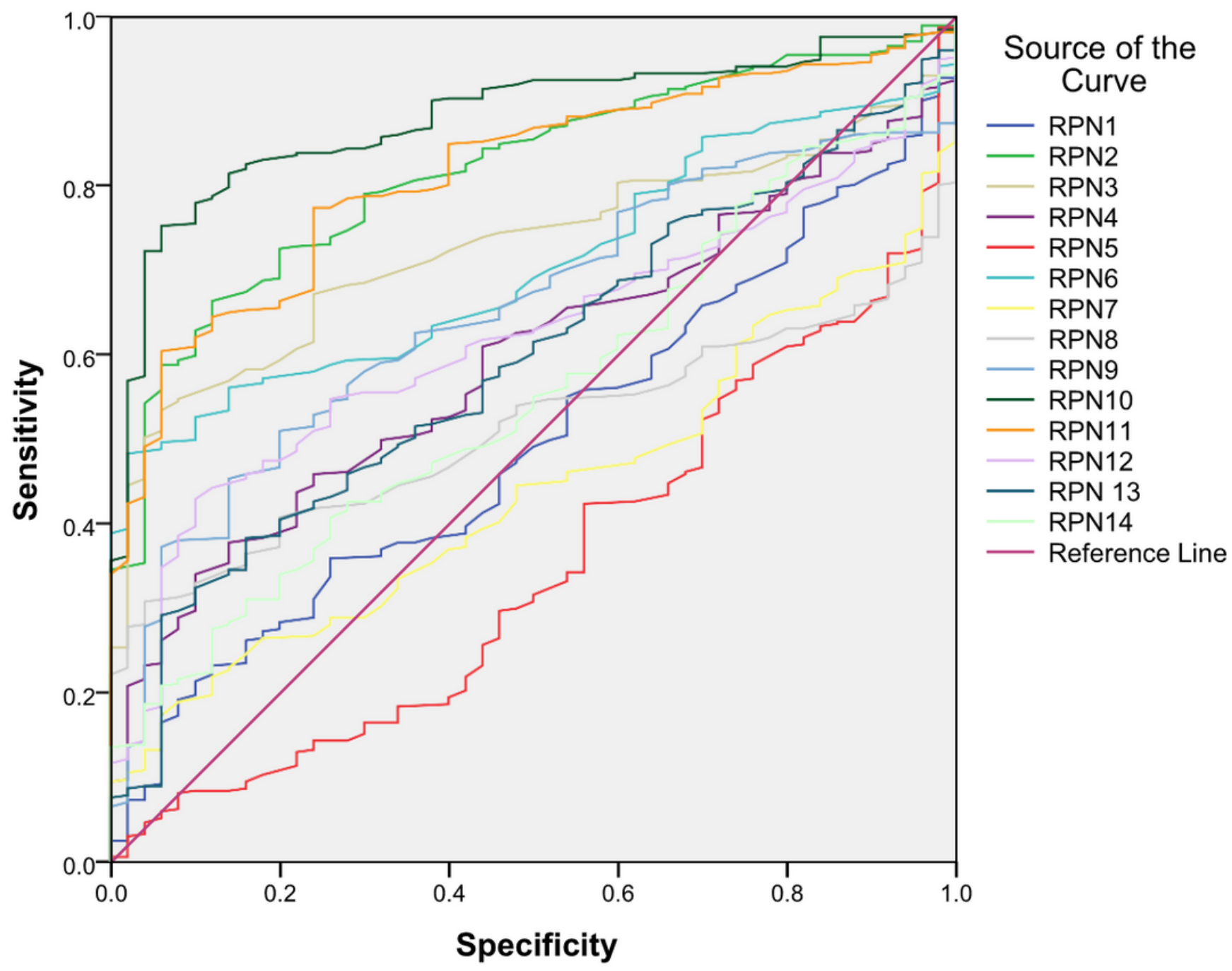

Figure 4

The ROC curve for analyzing of RPNs diagnostic value. 

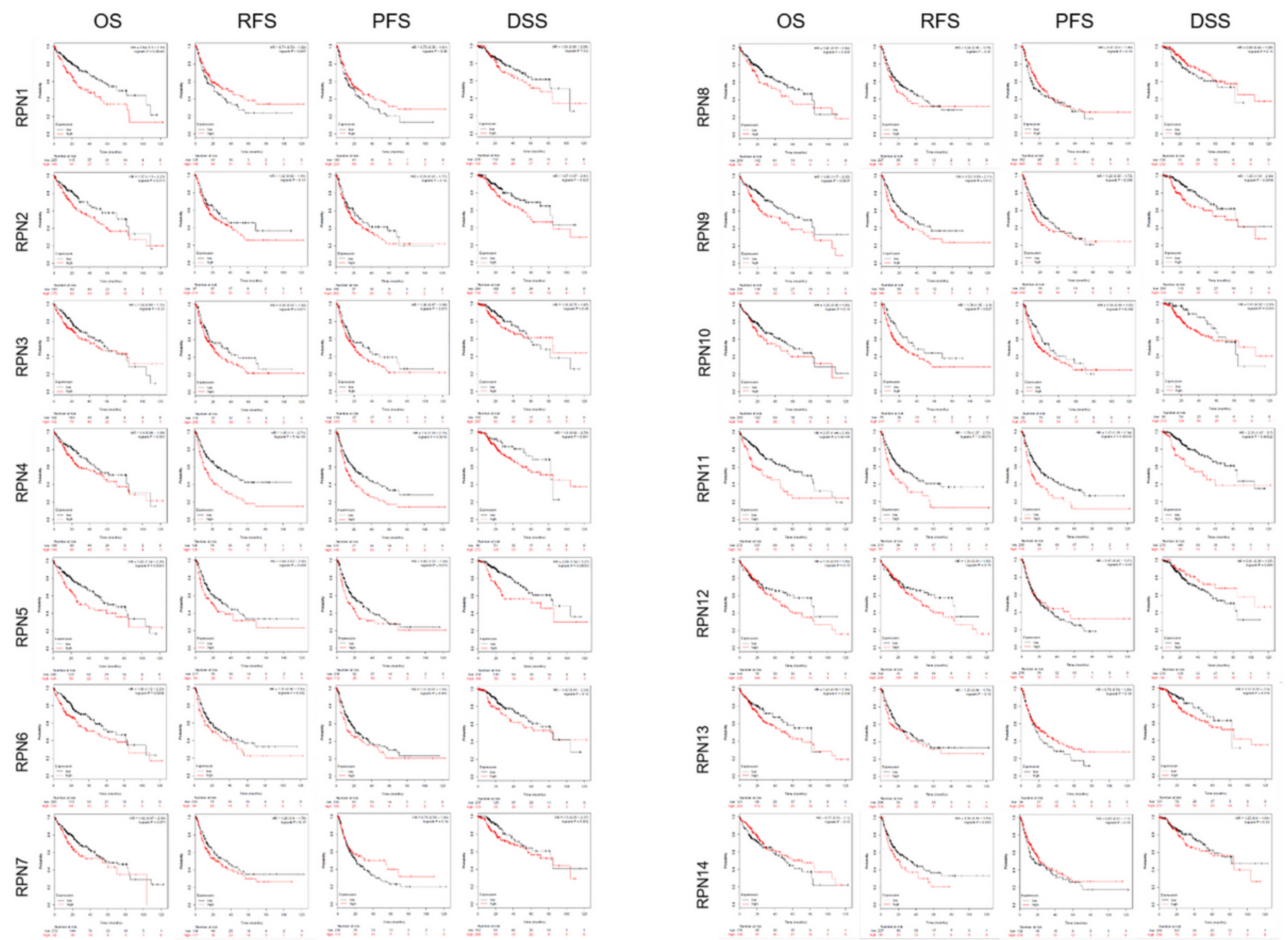

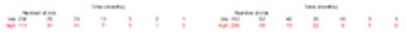

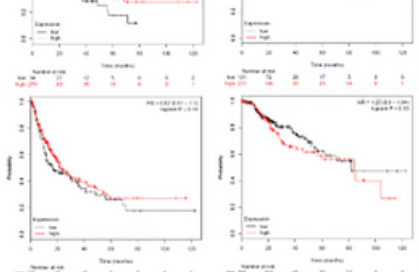

Figure 5

The Prognostic value of mRNA expression for distinct RPNs in HCC (Kaplan-Meier Plotter) 
A

RPN1 $0.3 \%$. H.

RPN2

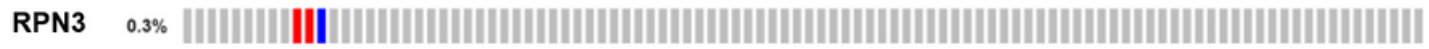

RPN4 $\quad 0.1 \%$. H.

RPN5 $\quad 1.4 \%$ |

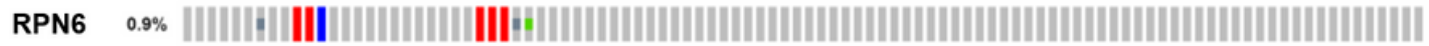

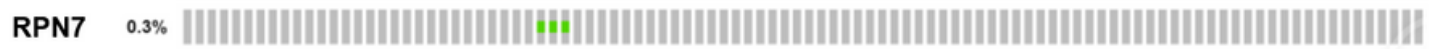

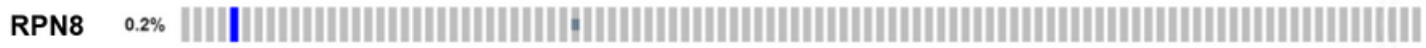

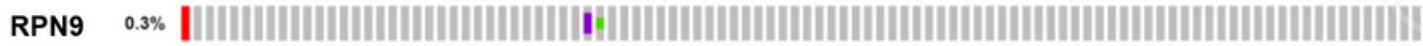

RPN10 $5 \%$.

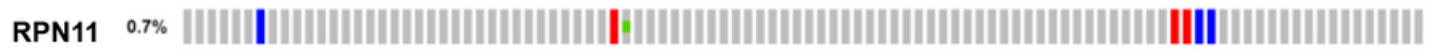

RPN12

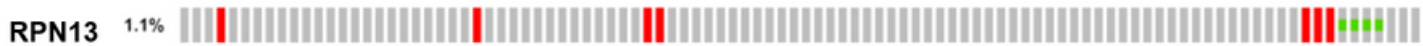

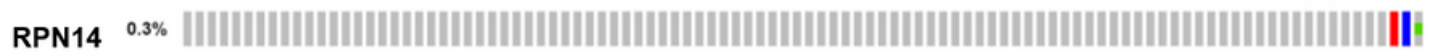

if Truncating Mutation (unknown sionificance) If Fusion | Amplifcation | Deep Delebion I No altorations

B

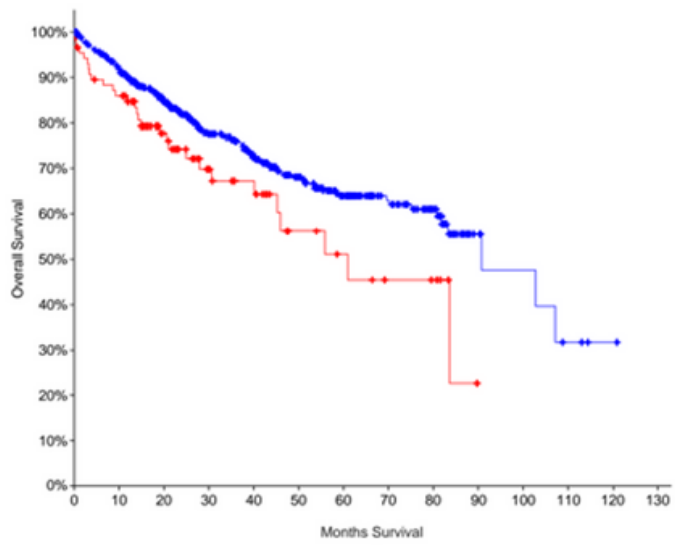

Logrank Test P.Vatue: 0.0258

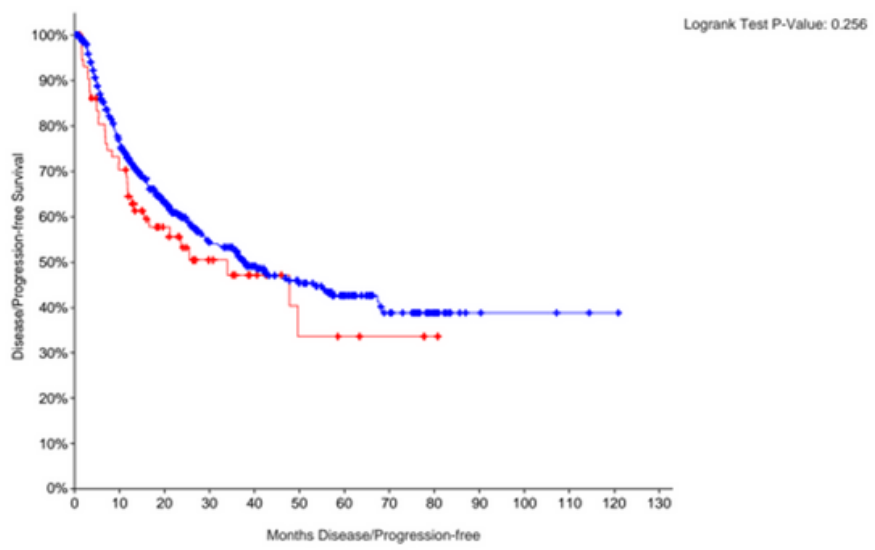

Overall Survival Kaplan-Meier Estimate

- Cases with Alteration(s) in RPNs

a Cases without Alteration(s) in RPNs

Figure 6

Genomic alterations of RPN of HCC (cBioPortal) A Oncoprint of RPNs alteration in HCC. B Survival analysis of patients with or without mutation. 

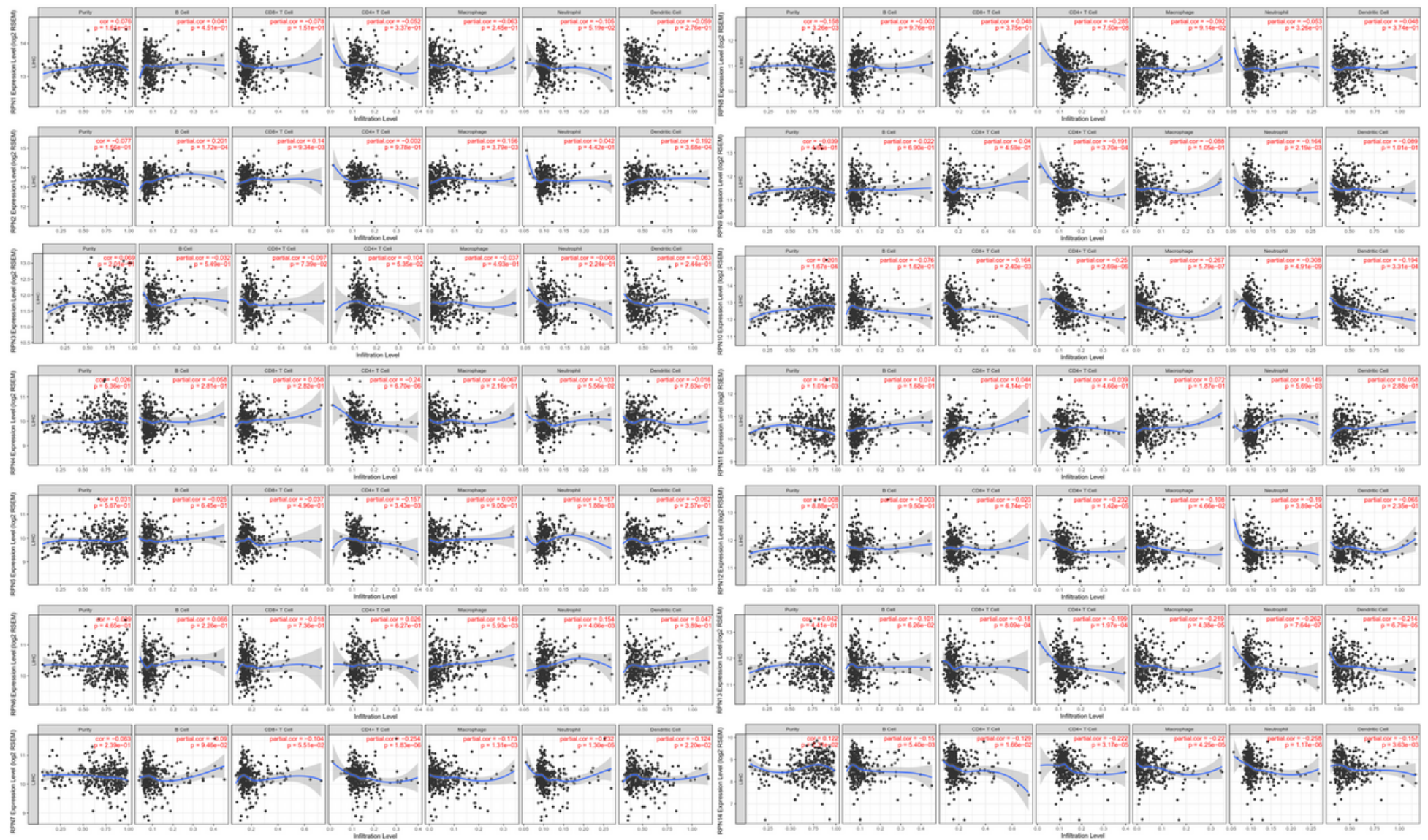

Figure 7

The correlation between different expressed RPNs and immune cell infiltration in HCC patients (TIMER).

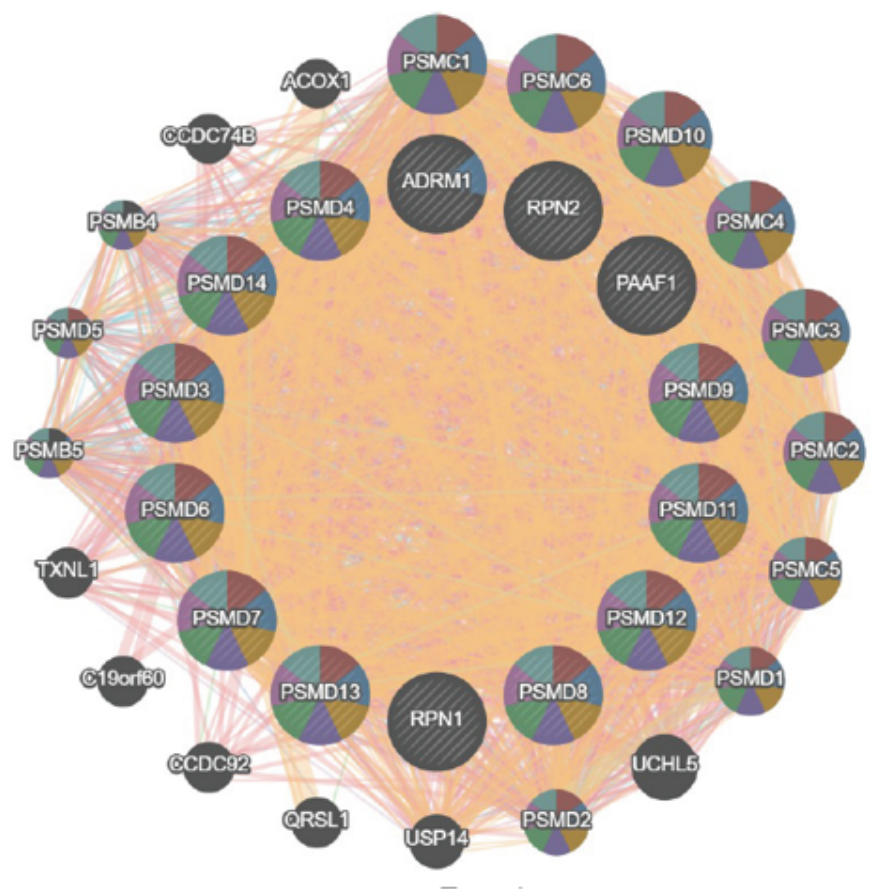

\section{Networks \\ [1] Predicted \\ a Physical Interactions \\ Pathway \\ 1. Co-expression \\ 1. Shared protein domains \\ Co-localization \\ Genetic Interactions}

\section{Functions}

- proteasome accessory complex

proteasome complex

- regulation of cellular amino acid metabolic process

DNA damage response, signal transduction by p53 class mediator resulting in cell cycle arrest

- signal transduction involved in mitotic DNA damage checkpoint

- signal transduction involved in DNA integrity checkpoint

negative regulation of ubiquitin-protein ligase activity involved in mitotic cell cycle 
Figure 8

Gene-gene interaction network of different expressed RPNs (GeneMANIA).

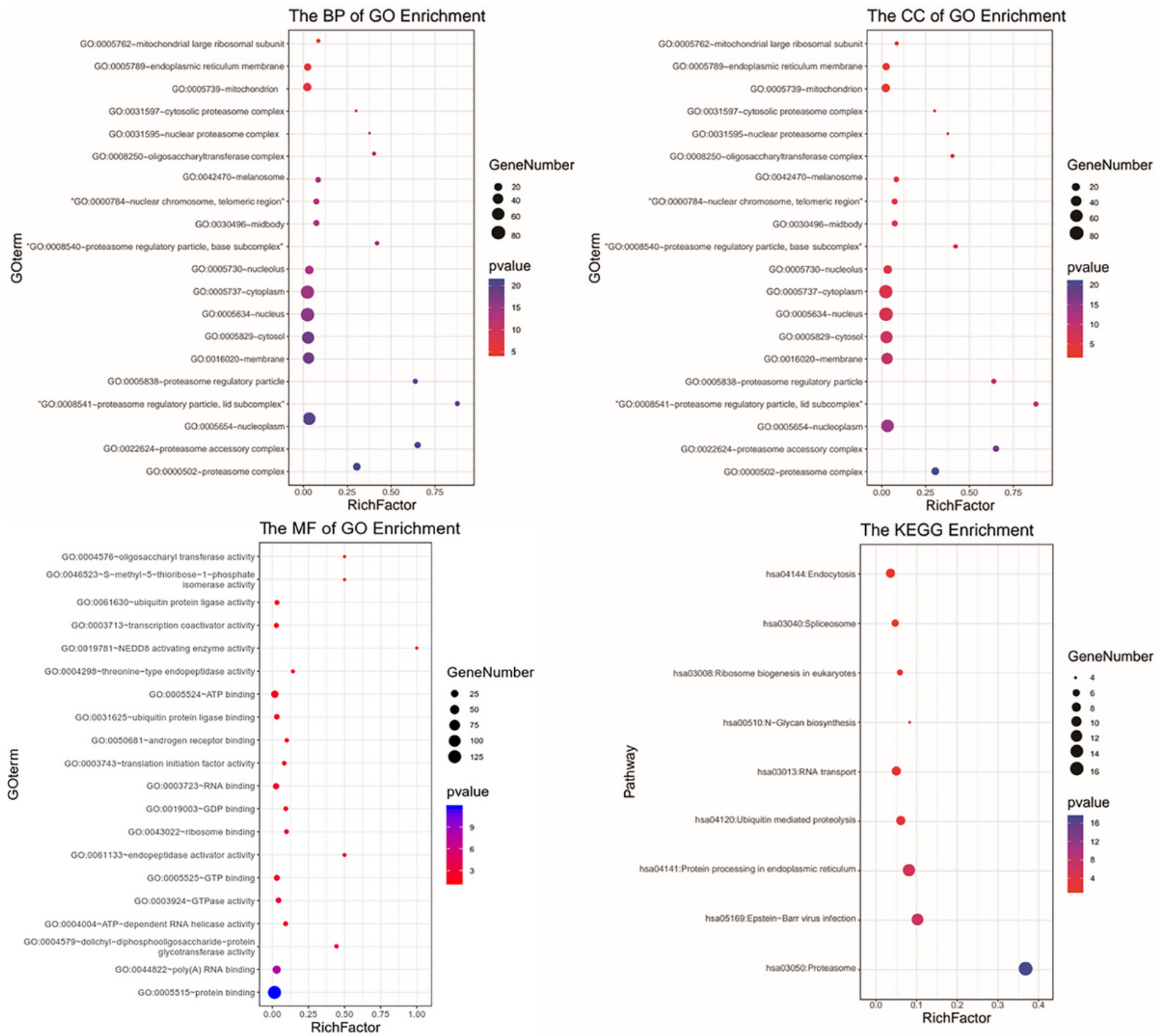

Figure 9

Predicted functions and pathways of RPNs. (BP, CC, MF, and KEGG) (String). 
A

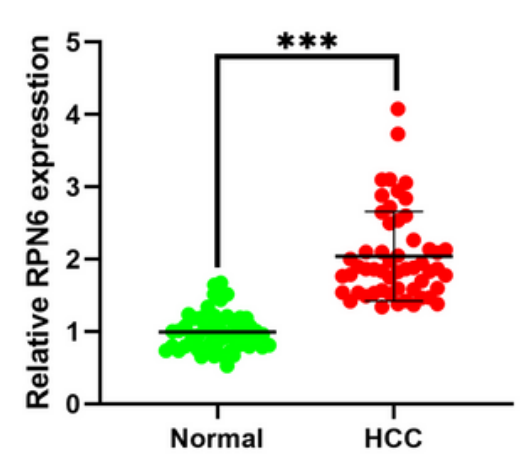

B

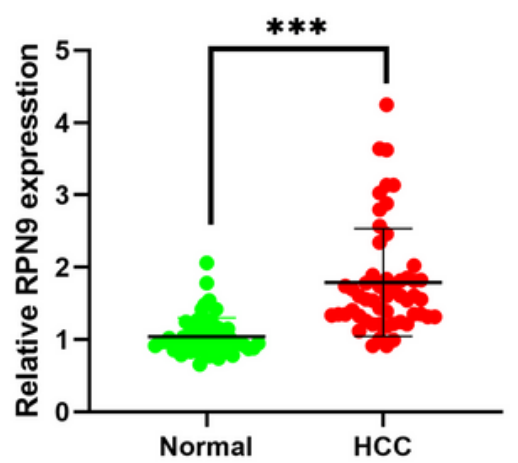

C

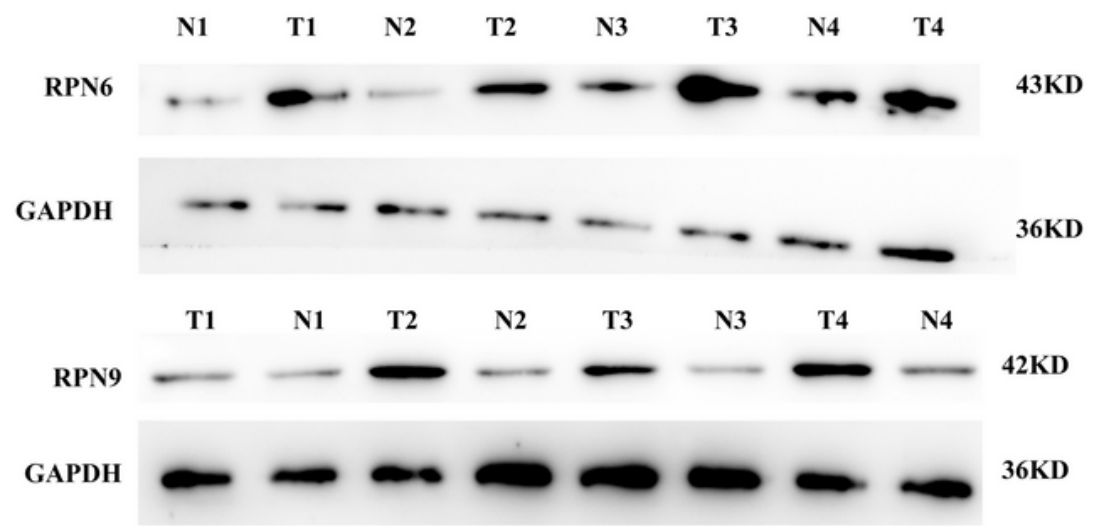

D

$\mathbf{E}$
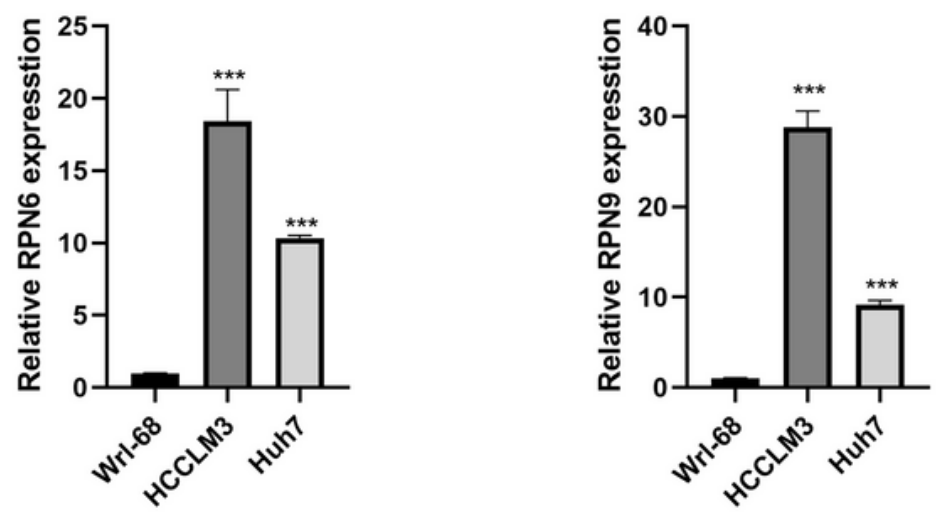

\section{Figure 10}

RPN6 and RPN9 are upregulated in HCC tissues and cell lines. a. RPN6 mRNA expression was markedly elevated in HCC tissues relative to their normal counterparts determined by RT-qPCR. b. RPN9 mRNA expression was markedly elevated in HCC tissues relative to their normal counterparts determined by RTqPCR. c. Western blot analysis was employed to confirm the expression of RPN6 and RPN9 in human HCC compared with the adjacent normal tissues. T tumors, $\mathrm{N}$ adjacent normal tissues. $\mathrm{d}$. RPN6 mRNA 
expression was markedly elevated in HCC cell lines than normal. e. RPN9 mRNA expression was markedly elevated in HCC cell lines than normal.

A
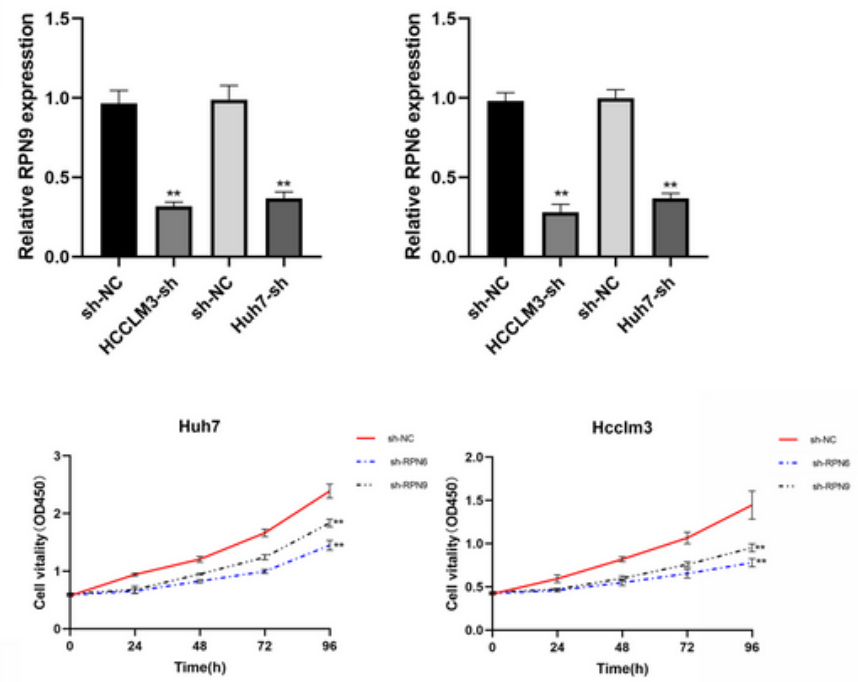

C
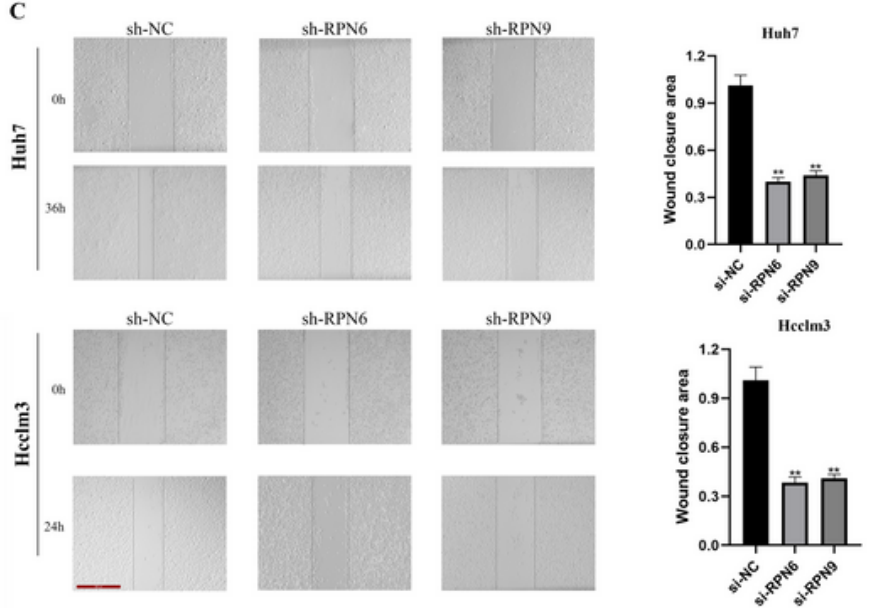

D
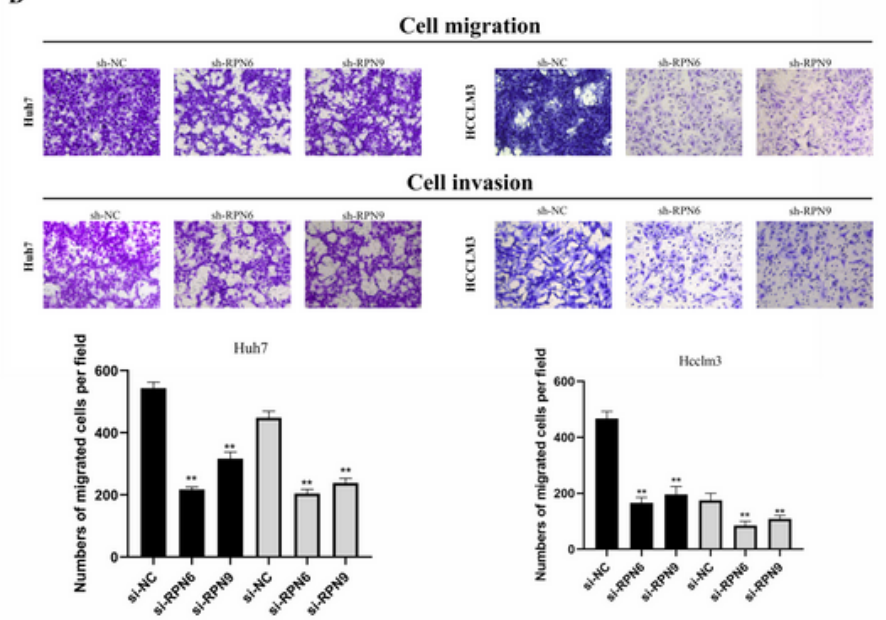

Cell invasion
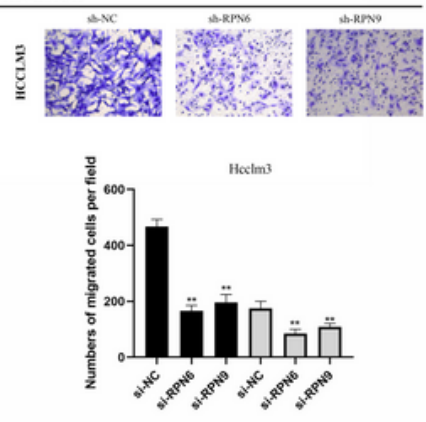

\section{Figure 11}

Knockdown of RPN6 and RPN9 suppresses the proliferation, migration and invasion of HCC cells in vitro.

a. RT-qPCR analysis was employed to examine the efficiency of RPN6 and RPN9 knockdown b. CCK-8 assays results for RPN6 and RPN9 knockdown in Hcclm3 and Huh7 cells c. Wound-healing assay was 
performed to measure the migration ability of these cells e. Transwell assays were used to measure the migration ability of these cells.

\section{Supplementary Files}

This is a list of supplementary files associated with this preprint. Click to download.

- TableS1.doc 